OPEN ACCESS

Edited by:

Sujin Yang,

Yonsei University, South Korea

Reviewed by:

Andree Hartanto,

Singapore Management University,

Singapore

Ruth Ford,

Anglia Ruskin University,

United Kingdom

*Correspondence:

Rosemarie E. Perry

rosemarie.perry@nyu.edu

Specialty section: This article was submitted to

Developmental Psychology,

a section of the journal

Frontiers in Psychology

Received: 04 June 2018 Accepted: 03 August 2018 Published: 28 August 2018

Citation:

Perry RE, Braren SH, Blair C and the Family Life Project Key Investigators

(2018) Socioeconomic Risk and

School Readiness: Longitudinal Mediation Through Children's Social Competence and Executive Function.

Front. Psychol. 9:1544.

doi: 10.3389/fpsyg.2018.01544

\section{Socioeconomic Risk and School Readiness: Longitudinal Mediation Through Children's Social Competence and Executive Function}

\author{
Rosemarie E. Perry ${ }^{*}$, Stephen H. Braren, Clancy Blair and the Family Life Project Key \\ Investigators
}

Neuroscience and Education Laboratory, Department of Applied Psychology, Institute of Human Development and Social Change, New York University, New York, NY, United States

The association of socioeconomic status with academic readiness and school achievement is well established. However, the specific contributions of cognitive and social aspects of self-regulation, and potential reciprocal relations between them in the prediction of school readiness and early school achievement have not previously been examined. This study examined mediational processes involving children's executive function (EF) skills at 58 months and Grade 1 (G1) and social competence in Kindergarten (K) and $\mathrm{G} 1$, as potential pathways by which early-life poverty-related risks influence Grade 2 (G2) math and reading achievement. Data came from the Family Life Project, which is a prospective longitudinal study of 1,292 children and families followed from birth in primarily low-income, non-urban counties in Pennsylvania (PA) and North Carolina (NC). Autoregressive cross-lagged mediation analyses indicated that EF at 58 months through EF at G1 mediated negative associations between cumulative risk exposure and academic skills, with this pathway mediating $36 \%$ of the total effect. Furthermore, social competence at $\mathrm{K}$ through EF at G1 mediated negative associations between early-life cumulative socioeconomic risk and academic skills, mediating $16 \%$ of the total effect. These findings provide evidence that poverty-related risks can influence school readiness and academic achievement via EF. Additionally, these results provide preliminary support for the premise that social competence through EF is a pathway by which cumulative poverty-related risk predicts early academic competence. Our findings are consistent with studies demonstrating developmental associations between EF and social competence. Furthermore, our findings are consistent with prekindergarten programs for children in poverty that emphasize both cognitive and social aspects of self-regulation.

Keywords: executive function, social competence, early-life adversity, poverty, social skills, social behavior, development, longitudinal 


\section{INTRODUCTION}

Decades of research have converged on the finding that growing up in poverty can negatively impact a child's academic abilities and achievement throughout the lifespan (Lacour and Tissington, 2011; Solano and Weyer, 2017). Such socioeconomic disparities are globally observed and emerge early in life, with exposure to poverty increasing the probability that a child will enter school behind their more advantaged peers in emergent math and literacy skills (Ryan et al., 2006; Engle and Black, 2008). Longitudinal data suggest that early gaps in measures of academic readiness for socioeconomically underprivileged children persevere and amplify as children progress through school, contributing to the emergence of inequalities in health care, employment opportunities, and judicial involvement (Huffman et al., 2001). Furthermore, prior research has demonstrated that exposure to multiple povertyrelated risks are related to poorer child outcomes above and beyond the effects of any single factor (Evans et al., 2013). Thus, isolating early factors that might influence children's subsequent achievement has become of great importance for identifying children at high risk of early school failure, as well as the design of targeted preventative interventions.

Acknowledged factors by which to promote school readiness and later achievement include instructional strategies for building emergent literacy (letter recognition, phonemic sensitivity) and numeracy skills (counting) (Wasik et al., 2006; Howes et al., 2008). However, core cognitive and socialemotional skills have been demonstrated to be equally important facets of school readiness (Campbell and Stauffenberg, 2008; Blair and Raver, 2015; Eickmann et al., 2016). These broader competencies promote "readiness to learn," an essential precursor to successful content-based learning (Campbell and Stauffenberg, 2008; Blair and Raver, 2015; Eickmann et al., 2016). For example, throughout the preschool years, development of inhibitory control and prosocial behaviors fosters the ability to sit still, as well as listen and attend to instructions and rules (McClelland et al., 2006). Furthermore, children with high levels of cognitive control and social-emotional skills are more able to attend to academic tasks, follow teachers' instructions, plan, exchange knowledge with peers, model appropriate peer behavior, and devote resources to learning, relative to their less competent peers (Denham et al., 2013).

As it has become evident that core cognitive and socialemotional competencies are central to school readiness, it has been proposed that children living in poverty face a multitude of risks which threaten the acquisition of these core competencies (Kaiser et al., 2000; Blair and Razza, 2007; Hughes et al., 2010; Raver et al., 2013). Indeed, an increasing number of studies have provided evidence that both executive functions (EFs) (Blair and Razza, 2007; Nesbitt et al., 2013; Crook and Evans, 2014) and social competence (Murray and Malmgren, 2005; Bierman et al., 2008; Elias and Haynes, 2008) serve as pathways by which poverty-related risks can influence school readiness and academic achievement. EFs are higher order self-regulatory mechanisms that support planning and goal-directed behaviors that are important for daily life. Such processes include inhibitory control, cognitive flexibility, and working memory (Diamond, 2013). Social competence refers to prosocial skills that mediate positive interactions with others, such as peers and teachers (Raver and Zigler, 1997). While the prior literature has visibly demonstrated that both EFs and social competence are central to school readiness, prior studies have not examined the functional processes by which EFs and social competence together relate to poverty-related risk exposure and early academic performance.

Although considered distinct domains of development, mounting evidence suggests that EF and social competence skill acquisition might be functionally linked (Riggs et al., 2006). Indeed, a growing body of literature has explored how EF skills may influence the subsequent development of social competencies. Multiple studies have presented evidence that EF skills in the early academic grades predict social competence one to two years later (Riggs et al., 2004; Ciairano et al., 2007). In another noteworthy study, social competence mediated the relationship between EF and change in academic scores across one school year, as assessed in a sample of 7-12 years olds (Valiente et al., 2008). This same research team also found that social functioning, measured by social competence and behavioral functioning scores, mediated the relationship between effortful control at 6 years and academic scores at 12 years (Valiente et al., 2011). Additionally, peer acceptance has been shown to mediate the association between inhibitory control and math grades in a sample of 4th and 5th graders (Oberle and Reichl, 2013). Social-behavioral adjustment was also found to mediate the effect of $\mathrm{EF}$ on school readiness in a sample of preschoolers (Baptista et al., 2016). Similarly, another study utilizing a low-income sample demonstrated that inhibitory control predicted measures of social and emotional competence (Rhoades et al., 2009). Finally, the predictive effect of EF on social competence has been shown to span into adolescence, as evidenced by studies where EF prior to school entrance and/or during elementary school predicted social and academic competence in 6th graders (Jacobson et al., 2011) and 15-year olds (Holmes et al., 2016). It is possible that EFs are needed for engaging in prosocial interactions (e.g., maintaining focus, listening, inhibiting distractions or inappropriate behaviors, and mentalizing another's beliefs or emotions), and perhaps necessary for the development and maintenance of social competence skills and positive peer relationships (Bateson, 2005; Hughes and Ensor, 2007; Brock et al., 2009; Russ, 2016). Thus, it is possible that poverty-related disruption of EF development itself can underlie disparities in school readiness, but can further contribute to disparities in school readiness through disruption of social competence skill development.

Additional research has explored the concept that reciprocal paths, in which earlier social skills influence the subsequent development of EFs, may exist (Carlson, 2009; Lewis and Carpendale, 2009; Moriguchi, 2014; van Lier and DeaterDeckard, 2016). Indeed, it has long been theorized that humans develop higher mental functions within the context of interpersonal activity and social relationships (Luria, 1966; Vygotsky, 1978). For example, it has been proposed that various components of social interactions, such as communication with others, perspective-taking, and compliance to social norms, set 
the stage for developing and maintaining EFs (Vygotsky, 1978). This idea that EF development occurs via social interactions has been scientifically explored, primarily through the study of adult-child social interactions in scaffolding EFs (Landry et al., 2002; Bibok et al., 2009; Hughes and Ensor, 2009; Lewis and Carpendale, 2009; Blair et al., 2011; Roskam et al., 2014; de Wilde et al., 2016). However, a small but growing body of literature has assessed this in terms of peer interactions (Moriguchi, 2014; van Lier and Deater-Deckard, 2016). This body of literature has provided evidence that social interactions with peers are essential to developing self-regulation (Lindsey and Colwell, 2003) and EFs such as cognitive flexibility (Bateson, 2005) and inhibitory control (Peterson and Flanders, 2005). Moreover, experiencing problems with peers, as measured by items measuring peer rejection, victimization, and social exclusion has been shown to contribute to reduced EF skills later in childhood (Baumeister et al., 2002, 2005; Holmes et al., 2016). However, there is a lack of research regarding the predictive role of social competence, as assessed via prosocial skills and positive peer relationships, on the subsequent development of EFs, especially among atrisk populations. It is possible that social competence skills provide one with the ability to form and maintain positive, stable relationships, which in turn facilitate EF development by providing increased opportunities for social communication, perspective-taking, and adherence to social norms (Vygotsky, 1978; Baumeister et al., 2002, 2005). Thus, it is possible that the disruption of social competence skills can lead to a disruption of EF skill development and subsequent academic performance.

The present study aimed to identify developmental processes by which poverty-related risks can contribute to gaps in academic readiness and school achievement, by assessing the interplay between social competence and EFs across the first years of schooling. All data came from the Family Life Project, a prospective longitudinal research study following 1,292 children and families from birth, who are primarily of low socioeconomic status (Vernon-Feagans et al., 2013). Based on prior empirical and theoretical work, we hypothesized that EF and social competence would reciprocally influence each other across the early elementary school grades. More specifically, we hypothesized that EF through social competence, and social competence through EF would demonstrate cross-lagged mediation of the relationship between early-life poverty-related risk exposure and academic abilities in Grade 2 (G2). Thus, this study was designed to explore the developmental interrelations between EF and social competence as a function of poverty status, as it pertains to influencing early academic achievement. The present study bridges existing research regarding relations between early-life experience and $\mathrm{EF} /$ social competence with research on the significance of $\mathrm{EF}$ and social competence for school readiness. To the best of our knowledge, this is the first study to test reciprocal longitudinal paths between social competence and EF as mediators between povertyrelated risk exposure and early academic abilities. Thus, it contributes to an expanding body of literature exploring the reciprocal development of EFs and prosocial behaviors as children transition to formal learning settings. In doing so, it expands the developmental scope and generalizability of the existing literature, by contributing longitudinal data regarding mediational processes involving EF and social competence in a predominantly socioeconomically disadvantaged sample.

\section{MATERIALS AND METHODS}

\section{Participants}

This study's data come from the Family Life Project, a prospective longitudinal study of children who were born from Fall 2003 to 2004. Participants were recruited from families residing in three low-income counties in Eastern North Caroline (NC) and three low-income counties in Central Pennsylvania (PA). These regions were carefully chosen to be representative of the Black South (NC) and Appalachia (PA). Low-income families were oversampled in both $\mathrm{NC}$ and $\mathrm{PA}$, and African American families were oversampled in NC. Complex sampling procedures were used for recruitment, and the authors refer the reader to previously published materials for full details regarding the study design and sampling plan (Vernon-Feagans et al., 2013). The complete sample of the Family Life Project consisted of 1,292 families.

\section{Procedures}

Demographic data come from a dataset collected in families' homes when the target children were approximately 2, 6, 15, 24, 36 , and 58 months of age. Home visits were conducted by two trained research assistants assessing household characteristics, family demographics, child behavior, and parenting style in a mother-infant interaction task. $\mathrm{EF}$ data come from direct assessments conducted during the 36, 58-months and G1 home visits. Social competence data were collected at the Kindergarten (K) and Grade 1 (G1) school visits, via teacher completed questionnaires. Research assistants also visited children at their school in G2 and administered early academic achievement measures, including the Woodcock-Johnson III Tests of Achievement. Timepoints, measures, and age statistics for child $\mathrm{EF}$, social competence, and academic outcome assessments are summarized in Table 1.

This study was reviewed and approved by the Institutional Review Board at Pennsylvania State University and the Office of Human Research Ethics at the University of North Carolina. Written informed consent was obtained from all adult participants and from the parents/legal guardians of all non-adult participants, in accordance with the Declaration of Helsinki. All participation was voluntary, with participants being informed prior to the study that they could remove their consent at any time.

\section{Measures Covariates}

State of residence $(\mathrm{PA}=0, \mathrm{NC}=1)$ was used as a covariate in all analyses to control for site differences in variables. Additional demographic covariates were included in all analyses. Specifically, covariates were primary caregiver's report of child sex $($ Male $=0$, Female $=1$ ) and child race (not African American =0; African American =1) during the 2-months home visit, and age of the infant at the $\mathrm{K}$ data collection point. 
TABLE 1 | Timepoints, measures, and ages of child executive function (EF), social competence, and academic outcome assessments.

\begin{tabular}{|c|c|c|c|}
\hline Timepoint & Measure & $N$ & $\begin{array}{l}\text { Mean age in } \\
\text { months (SD) }\end{array}$ \\
\hline 36 months & $\begin{array}{l}\text { EF battery } \\
\text { (Operation Span, Silly Sounds, Animal } \\
\text { Go/No Go, Spatial Conflict, } \\
\text { Something's the Same) }\end{array}$ & 973 & $37.02(0.14)$ \\
\hline \multirow[t]{4}{*}{58 months } & EF: Operation Span & 983 & $60.28(0.25)$ \\
\hline & EF: Silly Sounds & 995 & $60.37(0.25)$ \\
\hline & EF: Animal Go/No Go & 980 & $60.39(0.25)$ \\
\hline & EF: Pick the Picture & 1004 & $60.37(0.25)$ \\
\hline \multirow[t]{3}{*}{ Kindergarten } & $\begin{array}{l}\text { Prosocial Behavior Subscale } \\
\text { (Social Competence Scale) }\end{array}$ & 985 & $71.63(0.30)$ \\
\hline & $\begin{array}{l}\text { Prosocial Behavior Subscale } \\
\text { (Strengths and Difficulties } \\
\text { Questionnaire) }\end{array}$ & 982 & $71.63(0.30)$ \\
\hline & Peer Relationships Scale & 977 & $71.61(0.30)$ \\
\hline \multirow[t]{6}{*}{ Grade 1} & EF: Hearts and Flowers & 991 & $83.57(0.31)$ \\
\hline & EF: Dimensional Change Card Sort & 827 & $83.57(0.31)$ \\
\hline & EF: Backward Word Span & 1033 & $83.52(0.31)$ \\
\hline & $\begin{array}{l}\text { Prosocial Behavior Subscale } \\
\text { (Social Competence Scale) }\end{array}$ & 931 & $83.33(0.30)$ \\
\hline & $\begin{array}{l}\text { Prosocial Behavior Subscale } \\
\text { (Strengths and Difficulties } \\
\text { Questionnaire) }\end{array}$ & 929 & $83.33(0.30)$ \\
\hline & Peer Relationships Scale & 929 & $83.33(0.30)$ \\
\hline \multirow[t]{2}{*}{ Grade 2} & Woodcock-Johnson III: Brief Reading & 1044 & $95.35(0.31)$ \\
\hline & $\begin{array}{l}\text { Woodcock-Johnson III: Applied } \\
\text { Problems }\end{array}$ & 1046 & $95.35(0.31)$ \\
\hline
\end{tabular}

All analyses also included levels of sensitive parenting as a covariate, to control for an indicator of positive social interactions with the primary caregiver during a free-play task. Parenting style was assessed during interactions between the primary caregiver and their infant during a $10 \mathrm{~min}$ semistructured, free-play task during the 6-, 15-, 24-, and 36months home visits. Caregivers were given instructions to play with their infant using a standardized set of toys. Highly trained coders scored mother-infant interactions from video recordings. Videos were coded for levels of caregivers' sensitivity, intrusiveness, detachment, stimulation, positive regard, and negative regard (National Institute of Child Health and Human Development Early Child Care Research Network, 1999; Cox and Crnic, Unpublished manuscript). Each dimension of behavior was coded from 1 ("not at all characteristic") to 5 ("highly characteristic"). Principle factor analyses of parenting measures was conducted using an oblique rotation (i.e., Promax) for each time point. Dimensions included sensitive parenting (the average of stimulation, sensitivity, positive regard, animation, and detachment (reverse scored)) and negative parenting (average of instrusiveness, detachment, and negative regard), although only sensitive parenting was used for the current study (Mills-Koonce et al., 2011; Vernon-Feagans et al., 2013).

Lastly, as a robustness check, early-life EF was included as a covariate for all analyses. This EF data came from a commonly used battery of EF tasks, which was administered at the 36months home visits. This battery was comprised of inhibitory control tasks, a working memory task, and an attention shifting task. The inhibitory control tasks included a Spatial Conflict task, an Animal Go/No-Go task, and a Silly Sounds task similar to the Stroop task. The working memory task was comprised of a Span-like task. The attention shifting task was essentially an item selection task, which was modeled after the Dimensional Change Card Sort task (Sulik et al., 2015). Using item response theory, which relies on a latent variable approach, an expected a posteriori (EAP) score was generated for each task. Full details about the computation of EAP scores and information regarding longitudinal measurement invariance of these scores has been previously described in detail elsewhere (Willoughby et al., 2012a). An average of EAP scores was computed to create a composite measure of EF ability at 36-months.

\section{Cumulative Risk}

Poverty-related risk exposure was represented by computing a cumulative risk composite at $6,15,24$, and 36 months from seven variables. These variables included family income-toneeds ratio, household density, neighborhood safety, maternal education, consistent partnership of a spouse/partner living in the home, maximum work hours of primary or secondary caregiver per week, and job prestige. Job prestige was coded using the National Opinion Research Center (NORC) coding system (Nakao and Treas, 1994). To create the continuous cumulative risk index, positively framed indicators were reversescored and each risk measure was standardized and averaged together, such that higher scores indicated higher risk $(\alpha=0.82)$. As previously reported, this cumulative risk index was originally created through the assessment of nine social risk factors that were demographic indicators of socioeconomic status or had been related to poverty in prior research (Vernon-Feagans et al., 2013). These nine factors included family income-toneeds ratio, household density, neighborhood safety, maternal education, consistently partnered parents, employment hours, and job prestige, as well as maternal health, and ratings of food insufficiency. Principle component analyses at each age revealed a single dominant factor accounting for 33-36\% of total variance among the nine indicators (Vernon-Feagans et al., 2013). With the exception of maternal health and ratings of food insufficiency, all indicators loaded on this factor. As an additional strategy, a within-family mean score was also computed from the repeated measures of each of the nine risk variables from the $6,15,24$, and 36 months visits. These across-time mean risk scores were moderately correlated with one another, with the exception of maternal health and ratings of food insufficiency. Furthermore, a principle components analysis of these across-time mean risk scores revealed a single dominant factor accounting for $39 \%$ of total variance among the nine indicators. Again, the same seven indicators loaded substantially on this main risk index (income-to-needs ratio, household density, neighborhood safety, maternal education, consistenly partnered parents, employment hours, and job prestige) (Vernon-Feagans et al., 2013). Both strategies of analyses support that early poverty-related risk can be represented by a single summary variable computed using 
repeated measures of risk indicators. For the present analyses, it was chosen to use the cumulative risk index as calculated from the across-time mean risk indicators because it was the most parsimonious measure.

\section{Social Competence}

Children's social competence was modeled as a latent factor comprised of teachers' ratings across three scales from three measures. Specifically, we used the Prosocial subscale from the Strengths and Difficulties Questionnaire (SDQ) (Goodman, 1997), the Prosocial subscale from the Social Competence Scale (Dodge et al., 1994), and the Peer Relationships Scale (Ladd and Profilet, 1996) as observed indicators.

During the $\mathrm{K}$ and G1 school visits, teachers completed the SDQ, a 25-item questionnaire for use with children aged 316 years old. Items were rated on a 3 point scale as not true (zero), somewhat true (one point), or certainly true (two points). The SDQ has five subscales (Emotional Symptoms, Conduct Problems, Hyperactivity/Inattention, Prosocial Behavior, and Peer Relationship Problems), however the current study used only the Prosocial Behavior subscale. The Prosocial subscale measures the amount of prosocial characteristics displayed by a child (e.g., "shares readily with other children"), with higher scores representing higher levels of prosocial behaviors. A comprehensive review has been previously published, indicating that the teacher-completed SDQ has satisfactory internal consistency $(\alpha=0.70)$, as well as test-retest reliability $(r=0.77)$ for these scales (Stone et al., 2010). The Prosocial subscale from the Social Competence Scale was also completed by teachers. This subscale comprises four Likert-type items where children are rated in terms of their ability to successfully interact with others (e.g., "resolves problems with other children on his or her own," "cooperates"). Items were rated on a scale from "almost never" (one point) to "almost always" (six points) with higher ratings indicating higher social competence. This scale shows acceptable internal consistency ( $\alpha=0.93$ ). Finally, teachers completed the Peer Relationships Scale, comprised of six Likert-type items rated from "almost never" (zero points) to "almost always" (five points) (e.g., "is liked by classmates"). Negatively framed items (e.g., "is teased or picked on by classmates") were reverse-scored to create a positively framed indicator of peer relationships.

\section{Executive Function (EF)}

EF was assessed at the 58 months and G1 home visits (Table 2). At 58 months, EF was measured using a common battery of EF tasks. The EF battery included inhibitory control, working memory, and attention shifting tasks. The inhibitory control tasks were a Silly Sounds task modeled after the Stroop task, and an Animal Go/No-Go task (Durston et al., 2002). The working memory task was an Operation Span task based on the work of Engle (2002) (Engle, 2002). The attention shifting task was a Pick the Picture item selection task modeled after the Flexible Item Selection Task (Jacques and Zelazo, 2001; Willoughby et al., 2011). These tasks are described in Table 2 and are further described and evaluated in detail elsewhere (Willoughby et al., 2010, 2012b; Willoughby and Blair, 2011). EAP scores were generated for every task and equated across time using a calibration sample. Using EAP scores for each task, EF was modeled as a latent variable at 58 months.

At G1, EF was modeled as a latent variable comprised of the Hearts and Flowers task, a measure of inhibition and attention shifting (Davidson et al., 2006), a Backward Word Span task assessing working memory (Davis and Pratt, 1996), and a Dimensional Change Card Sort task (Willoughby et al., 2011). For the Hearts and Flowers task, a target picture (heart or flower) was presented on one side of a laptop screen. Children were told to push a button on the keyboard's laptop that corresponded

TABLE 2 | Executive function (EF) tasks at 58 months and Grade 1.

\begin{tabular}{|c|c|c|}
\hline Timepoint & Measure & Description \\
\hline \multirow[t]{4}{*}{58 months } & Operation Span & $\begin{array}{l}\text { Children were shown an outline of a house containing a drawing of an animal and a colored dot. Children were asked to name } \\
\text { the animal and the color. Children were then shown the outline of the house again on a subsequent page and asked to recall } \\
\text { which animal was in the house. }\end{array}$ \\
\hline & Silly Sounds & $\begin{array}{l}\text { In this Stroop-like task, children were instructed to make the sound of a cat when presented with an image of a dog, and the } \\
\text { sound of a dog when presented with an image of a cat. }\end{array}$ \\
\hline & Animal Go/No Go & $\begin{array}{l}\text { This is a standard go/no go task presented in a flipbook format. Children were instructed to click a large button every time they } \\
\text { were presented with an image of an animal, except when an image of a pig was presented. }\end{array}$ \\
\hline & Pick the Picture & $\begin{array}{l}\text { In this self-ordered pointing task, children were presented with a set of pictures and instructed to pick each picture so that each } \\
\text { of the pictures "gets a turn." For example, for a set of pictures containing an apple and a cat, if the child picks the apple, they } \\
\text { must then pick the cat on the next page. The arrangement of pictures within each set was randomized so that children could not } \\
\text { rely on spatial information. }\end{array}$ \\
\hline
\end{tabular}

Grade $1 \quad$ Hearts and Flowers

Children were instructed to push buttons on a keyboard based on the image (heart or flower), and location of image on the keyboard's screen. For hearts, children were told to push a button on the same side of the keyboard as the heart's location on the screen. For flowers, children were told to push a button on the opposite side of the keyboard as the flower's location on the screen.

Dimensional Change Children were asked to shift between sorting a set of cards by their shape or color, first by one feature (e.g., shape), and then by Card Sort the other feature (e.g., color). Lastly, children were instructed to sort cards according to an audio cue played at the beginning of each trial identifying the feature by which they should sort.

Backward Word Children instructed to repeat a list of familiar, single-syllable and related words in reverse order (e.g., repeat "book, cup" as "cup, Span book"). 
with the picture's location on the display. For hearts, children were told to push the button on the same side of the target picture. For flowers, children were told to push the button on the opposite side of the target picture. Children were allowed instructional and practice trials, which could be repeated up to three times, if needed. Instructional/practice trials were followed by 20 hearts-only trials, 12 flowers-only trials, and 33 mixed trials that included hearts and flowers. Children's accuracy was measured, with accuracy for the intermixed section of the task being used for the current study's purposes.

For the Backward Word Span task children were requested to repeat a list of familiar single-syllable and related words (but not semantically related) in reverse order (i.e., if the instructor says "book, cup," the child is to say "cup, book"). Children were allowed instructional and practice trials, which could be repeated up to three times, if needed. For the task, the list of words to be repeated increased with every successful trial over the course of six trials. The task concluded when the child made three consecutive errors, with their score being recorded as the highest number of words correctly recalled.

For the Dimensional Change Card Sort task, children were asked to sort cards by two features, shape or color. In the first segment of the task, children were told to sort cards by either shape or color. In the second segment, children were told to sort cards by the other feature. In the third and final segments, trials were mixed such that children were told to sort 50 cards according to an audio cue played at the beginning of each trial identifying the feature by which they should sort. The percentage of correct responses during these mixed trials was used for the current study's purposes.

\section{Academic Outcomes}

Academic Outcomes was modeled as a latent variable of skills related to reading and math, which were evaluated during the G2 school visits via the Woodcock-Johnson III Tests of Achievement. The Woodcock-Johnson III Tests of Achievement is a norm-referenced battery of subtests used to measure scholastic aptitude, spoken language, and academic achievement (Woodcock et al., 2001). The Brief Reading subtest was used as a measure of reading achievement, while the Applied Problems subtest was used as a measure of math achievement. The validity and reliability of the Woodcock-Johnson III Tests of Achievement have been previously established and elaborated on elsewhere (Woodcock et al., 2001).

\section{Missing Data}

The entire study sample consisted of 1,292 families at the 2 -months home visit, with 1,204 children seen at 6-months postpartum, 1,169 children at 15-months, 1,144 children at 24-months, 1,123 children at 36-months, 1,099 at 58 months, 1,063 at $\mathrm{K}, 1,093$ at G1, and 1,049 at G2. Complete data were available for sex and race of the target child, as well as state of residence. Participants were included in the analysis if they were not missing data for one or more assessments of the Woodcock-Johnson III Tests of Achievement. This resulted in an analytic sample of $N=1,044$, which was used for all analyses. To assess possible differential attrition, variables for which there was complete information were examined, including race, sex, child at age $\mathrm{K}$, and cumulative risk, with few variables indicating differences between children who were present vs. missing at each data collection time point. Specifically, child race and age demonstrated differences, such that children not included in our analyses were more likely to be African American and older. Complete information related to missing data is available upon request to the first author. Full information maximum likelihood (FIML) estimation was used to reduce bias in estimates related to missing data (Enders, 2010).

\section{Statistical Analysis}

All data were tabulated and statistically analyzed using IBM SPSS Statistics Version 21.0, and Mplus softwares. Descriptive analyses and bivariate correlations were computed for all study variables in SPSS 21.0. Structural equation models testing autoregressive cross-lagged mediation were estimated using the bootstrapping procedure (5,000 bootstraps) (Shrout and Bolger, 2002) in Mplus 7 software (Muthén and Muthén, 1998-2012). All parameter estimates are reported as standardized effects (Preacher and Hayes, 2008). Model fit was evaluated using the Comparative Fit Index (CFI), the root mean squared error of approximation (RMSEA), and the standardized root square mean residual (SRMR) fit indices, with CFI $\geq 0.95$, RMSEA $<0.05$, and SRMR $<0.08$ being indicative of good fit (Kline, 2015). The raw data of this manuscript will be made available by the authors to any qualified researcher, without reservation.

\section{RESULTS}

\section{Preliminary Analysis}

Descriptive statistics and bivariate correlations among all study variables appear in Tables 3 and 4, respectively. The overall pattern of correlations was consistent with the study's hypothesis. Specifically, our independent variable (povertyrelated cumulative risk exposure) was negatively associated with our proposed mediating variables: Cumulative Risk was negatively associated with each observed indicator of social competence at $\mathrm{K}$ and G1, as well as EF at 58 months and G1. Furthermore, our proposed mediating variables were positively associated with academic outcomes at G2: Social behavior measures at K and G1 were positively related to Brief Reading and Applied Problems at G2. EF measures were also positively related to Brief Reading and Applied Problems at G2. Additionally, Cumulative Risk was negatively associated with Brief Reading and Applied Problems at G2. Finally, our proposed mediating variables were positively associated with each other: Social behavior measures at K and G1 were positively related to EF at 58 months and EF at G1. Together, this pattern of significant associations provided support for our hypothesized mediating model (Figure 1), which was tested below.

\section{Structural Equation Modeling}

To examine relationships between Cumulative Risk, measures of social competence and EF, we used structural equation modeling. We modeled Social Competence as a latent variable at $\mathrm{K}$ and G1 with the Prosocial subscales of the SCS and SDQ, as well as 
TABLE 3 | Descriptive statistics for observed variables.

\begin{tabular}{|c|c|c|c|c|c|}
\hline & $N$ & $\begin{array}{l}\text { Mean } \\
\text { or } \%\end{array}$ & $S D$ & Minimum & Maximum \\
\hline Race (\% African American) & 1292 & $42 \%$ & - & - & - \\
\hline Sex (\% Male) & 1292 & $51 \%$ & - & - & - \\
\hline State of Residence (\% NC) & 1292 & $60 \%$ & - & - & - \\
\hline Child Age at K (years) & 1072 & 5.99 & 0.31 & 5.40 & 7.35 \\
\hline $\begin{array}{l}\text { Cumulative Risk (6-36 } \\
\text { months) }\end{array}$ & 1235 & -0.01 & 0.69 & -2.66 & 2.19 \\
\hline $\begin{array}{l}\text { Sensitive Parenting (6-36 } \\
\text { months) }\end{array}$ & 1221 & 2.85 & 0.66 & 1.00 & 4.65 \\
\hline Prosocial Behavior SCS (K) & 985 & 4.33 & 1.15 & 1.00 & 6.00 \\
\hline Prosocial Behavior SDQ (K) & 982 & 1.54 & 0.47 & 0.00 & 2.00 \\
\hline Peer Relationships (K) & 977 & 3.40 & 0.61 & 0.50 & 4.00 \\
\hline Prosocial Behavior SCS (G1) & 931 & 4.27 & 1.18 & 1.00 & 6.00 \\
\hline $\begin{array}{l}\text { Prosocial Behavior SDQ } \\
\text { (G1) }\end{array}$ & 929 & 1.52 & 0.49 & 0.00 & 2.00 \\
\hline Peer Relationships (G1) & 929 & 3.34 & 0.66 & 0.00 & 4.00 \\
\hline EF (36 months) & 973 & -0.54 & 0.54 & -1.98 & 1.18 \\
\hline Operation Span (58 months) & 983 & 0.34 & 0.68 & -1.71 & 1.98 \\
\hline Silly Sounds (58 months) & 995 & 0.21 & 0.78 & -1.98 & 1.41 \\
\hline $\begin{array}{l}\text { Animal Go/No Go (58 } \\
\text { months) }\end{array}$ & 980 & 0.28 & 0.69 & -1.98 & 0.85 \\
\hline Pick the Picture (58 months) & 1004 & 0.28 & 0.82 & -2.54 & 2.25 \\
\hline H\&F \% correct (G1) & 991 & 0.80 & 0.18 & 0.15 & 1.00 \\
\hline DCCS \% correct (G1) & 827 & 0.85 & 0.14 & 0.25 & 1.00 \\
\hline Backward Word Span (G1) & 1033 & 2.43 & 0.74 & 1.00 & 5.00 \\
\hline WJ: Brief Reading (G2) & 1044 & 471.60 & 22.53 & 347.00 & 518.00 \\
\hline WJ: Applied Problems (G2) & 1046 & 472.43 & 20.85 & 318.00 & 536.00 \\
\hline
\end{tabular}

K, Kindergarten; G1, Grade 1; G2, Grade 2; SCS, Social Competence Scale; SDQ, Strengths \& Difficulties Questionnaire; EF, Executive Function; H\&F, Hearts \& Flowers; DCCS, Dimensional Change Card Sort; WJ, Woodcock Johnson.

the Peer Relationships Scale as indicators. Similarly, we modeled $\mathrm{EF}$ at 58 months and G1 as a latent variable with inhibitory control, working memory, and attention set shifting tasks as indicators. Lastly, we modeled Academic Outcomes at G2 using a latent variable with the Brief Reading and Applied Problems as indicators. We included observed variables for state of residence, race of child, sex of child, age of child, sensitive parenting (636 months), and EF at 36 months as covariates. Additionally, observed variables of family income-to-needs ratio, household density, neighborhood safety, maternal education, consistent partnership of a spouse or partner, maximum work hours of primary or secondary caregiver per week, and job prestige were used to compute a poverty-related Cumulative Risk index.

\section{Measurement Model}

Prior to addressing our primary research question, we evaluated our measurement model that included the following latent variables: Social Competence at K, Social Competence at G1, $\mathrm{EF}$ at 58 months and G1, and Academic Outcomes at G2. This measurement model fit the data well: CFI $=0.99$; RMSEA $=0.030$ (90\% confidence interval [0.023, 0.037]); $\mathrm{SRMR}=0.027$. Factor loadings of observed indicators on latent variables are reported in Table 5. Parameter estimates demonstrated that loadings were statistically significant in the expected direction, and that all latent variances were statistically significant. The correlation between EF and Social Competence latent variables was relatively high for both the K/58 months time point $(\phi=0.42)$ and G1 time point $(\phi=0.43)$.

Before testing mediation, we also evaluated independent, direct associations with early-life Cumulative Risk predicting Social Competence in $\mathrm{K}$ and G1, EF at 58 months and G1, and academic outcomes in G2. As expected, Cumulative Risk negatively predicted Academic Outcomes $(\beta=-0.220$, $S E=0.046, p<0.001)$. Cumulative Risk also negatively predicted $\mathrm{EF}$ at 58 months $(\beta=-0.169, S E=0.049, p=0.001)$ and G1 $(\beta=-0.165, S E=0.052, p=0.002)$. Finally, Cumulative Risk negatively predicted Social Competence at $\mathrm{K}(\beta=-0.162$, $S E=0.044, p<0.001)$ and $\mathrm{G} 1(\beta=-0.123, S E=0.045$, $p=0.006)$.

\section{Structural Model}

Figure 1 displays our hypothesized structural model (without covariates). In this model, we estimated an autoregressive crosslagged mediation model that included all variables of interest. Specifically, we examined direct effects of all variables of interest on Academic Outcomes (G2), EF (58 months and G1), and Social Competence ( $\mathrm{K}$ and $\mathrm{G} 1$ ). Furthermore, we examined indirect effects of Cumulative Risk on Academic Outcomes through EF (58 months, G1), or Social Competence (K, G1) separately to determine the extent to which these variables mediate effects of poverty-related Cumulative Risk on child early Academic Outcomes. Indirect effects of Cumulative Risk on Academic Outcomes through EF at 58 months through EF at G1, as well as through Social Competence at $\mathrm{K}$ through Social Competence at G2 were also examined. Finally, indirect effects of Cumulative Risk on Academic Outcomes through EF (58 months) through Social Competence (G1) (and vice versa: through Social Competence $[\mathrm{K}]$ through EF [G1]) were examined. As previously, we controlled for our covariates on each endogenous variable in the model.

The observed structural model fit the data well: $\mathrm{CFI}=0.96$; RMSEA $=0.039(90 \%$ confidence interval $[0.035,0.044])$; $\mathrm{SRMR}=0.041$ (Figure 2). All coefficients presented are standardized estimates and thus reflect changes in standard deviations. Direct effects are reported in Table 6. Of particular note, Cumulative Risk was not directly associated with Social Competence or EF at G1, but was negatively associated with Social Competence at $\mathrm{K}$ and $\mathrm{EF}$ at 58 months. Furthermore, $\mathrm{EF}$ at G1 was negatively associated with Academic Outcomes. However, Social Competence at K and G1, as well as EF at 58 months were not significantly associated with Academic Outcomes at G2. Social Competence at $\mathrm{K}$ was positively associated with EF and Social Competence at G1. EF at 58 months was also positively associated with EF and Social Competence at G1.

\section{Cross-Lagged Mediation}

Our primary hypothesis was that EF (58 months) through Social Competence (G1), and Social Competence (K) through EF (G1) 


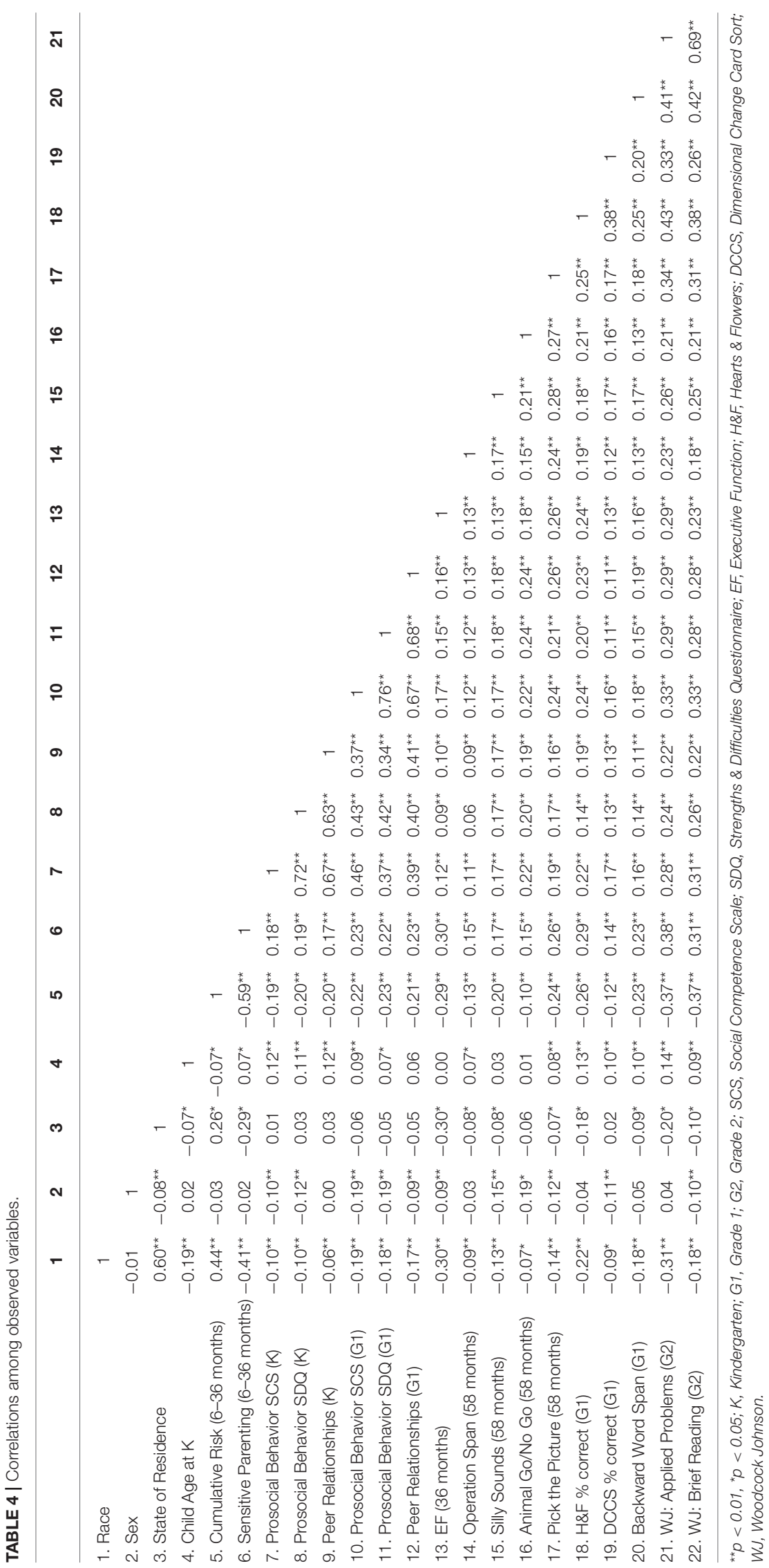




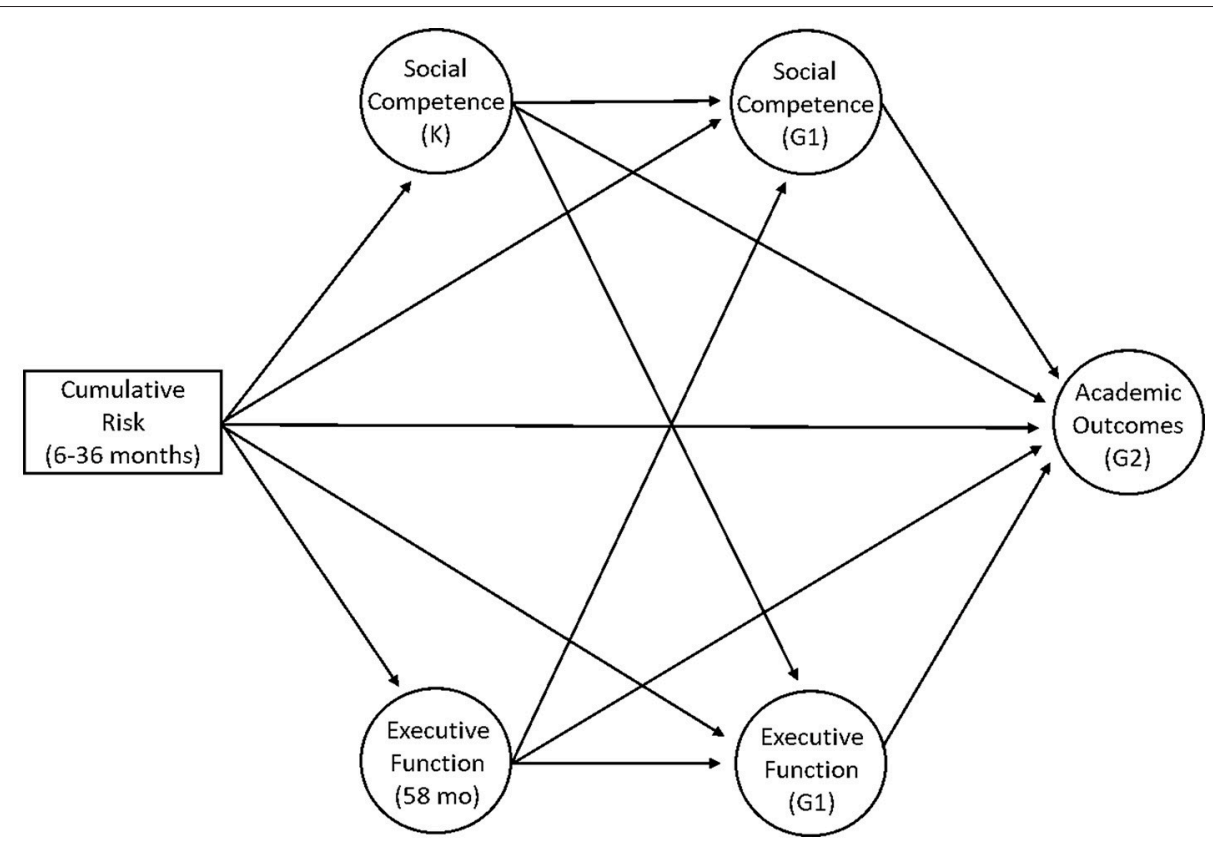

FIGURE 1 | Hypothesized autoregressive cross-lagged mediation model relating poverty-related cumulative risk (6-36 months), social competence (K \& G1), executive function (58 months \& G1), and academic outcomes (G2). K, Kindergarten; G1, Grade 1; G2, Grade 2; mo, months. Covariates are not shown.

TABLE 5 | Loadings of observed indicators on latent variables.

\begin{tabular}{lll}
\hline Latent variable & Indicators & $\boldsymbol{\beta}$ \\
\hline Social Competence (K) & Prosocial subscale (SDQ) & 0.82 \\
& Prosocial subscale (SCS) & 0.87 \\
Social Competence (G1) & Peer Relationships Scale & 0.77 \\
& Prosocial subscale (SDQ) & 0.86 \\
& Prosocial subscale (SCS) & 0.87 \\
Executive Function (58 months) & Peer Relationships Scale & 0.80 \\
& Operation Span & 0.40 \\
& Silly Sounds & 0.49 \\
& Animal Go/No Go & 0.51 \\
Executive Function (G1) & Pick the Picture & 0.62 \\
& H\&F & 0.61 \\
Academic Abilities (G2) & Backward Word Span & 0.53 \\
& DCcS & 0.51 \\
& WJ: Brief Reading & 0.80 \\
& WJ: Applied Problems & 0.86
\end{tabular}

All coefficients are standardized and significant at $p<0.0001 . K$, Kindergarten; G1, Grade 1; G2, Grade 2; SCS, Social Competence Scale; SDQ, Strengths and Difficulties Questionnaire; H\&F, Hearts \& Flowers; DCCS, Dimensional Change Card Sort; WJ, Woodcock Johnson.

would demonstrate cross-lagged mediation of the relationship between early-life cumulative poverty-related risk exposure and academic abilities in Grade 2 (G2). To evaluate this hypothesis, we tested the indirect effects of Cumulative Risk (6-36 months) on Academic Outcomes at G2. Specifically, we tested indirect effects via serial pathways involving Social Competence ( $\mathrm{K}$ and G1) and EF (58 months \& G1). We also tested indirect paths between Cumulative Risk and Academic Outcomes through Social Competence and EF separately.

Table 7 displays the mediation results and indicates that Social Competence at K mediated the effects of Cumulative Risk on Academic Outcomes through EF at G1, with this pathway mediating $16 \%$ of the total effect. Additionally, EF at 58 months via $\mathrm{EF}$ at G1 significantly mediated the relationship between Cumulative Risk on Academic Outcomes, with this pathway mediating $36 \%$ of the total effect. Thus, Social Competence at $\mathrm{K}$ through $\mathrm{EF}$ at $\mathrm{G} 1$ was a significant mediating pathway even when accounting for mediation via $\mathrm{EF}$ at $\mathrm{K}$ through $\mathrm{EF}$ at G1. Furthermore, these significant mediating pathways occurred while controlling for EF at 36 months, which was a covariate in our model. However, EF at 58 months through Social Competence at G1 did not demonstrate cross-lagged mediation of the effects of Cumulative Risk on Academic Outcomes. Additionally, mediational pathways involving EF or Social Competence as independent mediators were not significant.

\section{DISCUSSION}

This study aimed to extend existing literature regarding potential developmental processes by which growing up in poverty can influence school readiness and academic achievement. Environmental influences on the development of EF and social competence, and the importance of EF and social competence for school readiness are emerging areas of research. However, no prior studies have sought to bridge these areas of research by exploring autoregressive cross-lagged mediational pathways involving social competence and EF development 


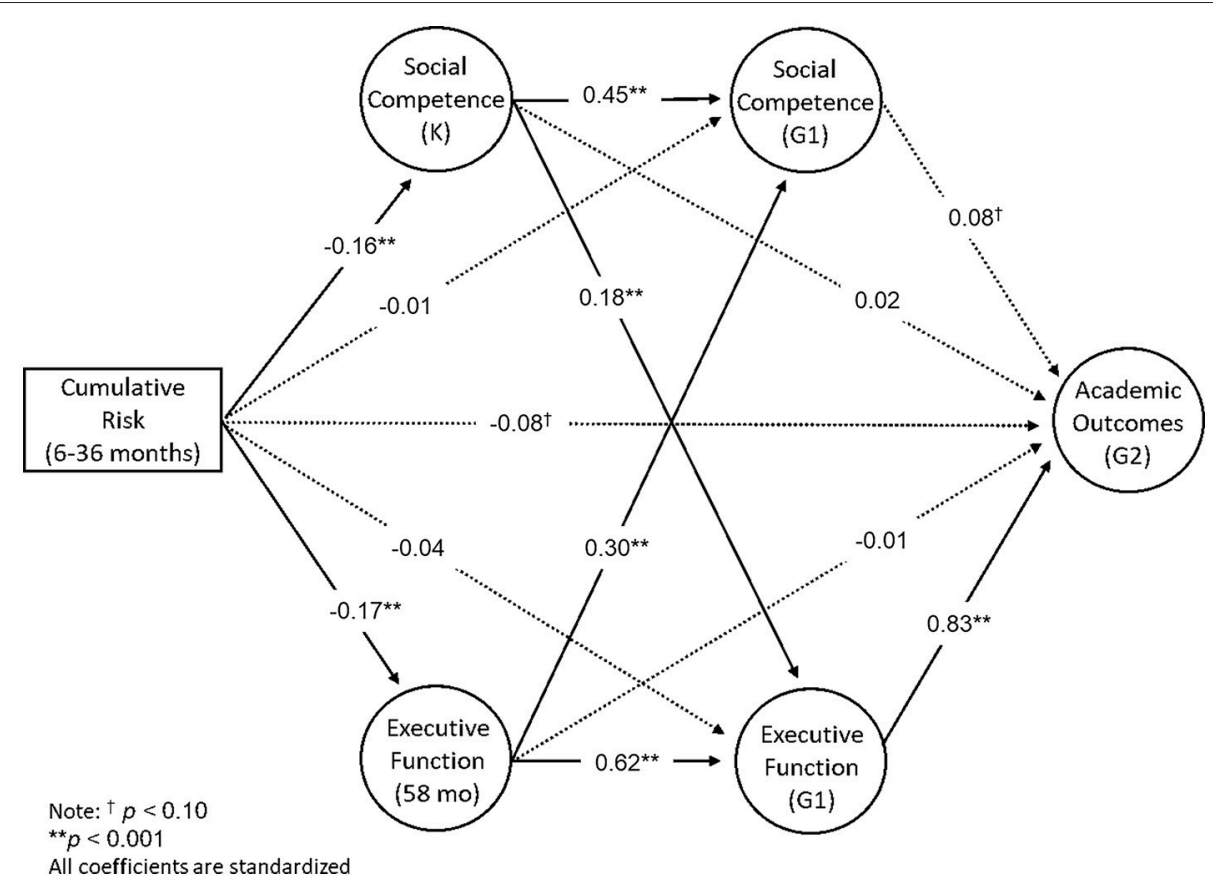

FIGURE 2 | Autoregressive cross-lagged mediation model relating poverty-related cumulative risk (6-36 months), social competence (K \& G1), executive function (58 months \& G1), and academic outcomes (G2). All coefficients are standardized ( $\beta$ ). All significant pathways are bolded. ${ }^{* \star} p<0.001,{ }^{\dagger} p<0.10, \mathrm{~K}, \mathrm{Kindergarten;}$ G1, Grade 1; G2, Grade 2; mo, months. Covariates are not shown.

TABLE 6 | Direct effects of models predicting social competence, executive function, and academic achievement.

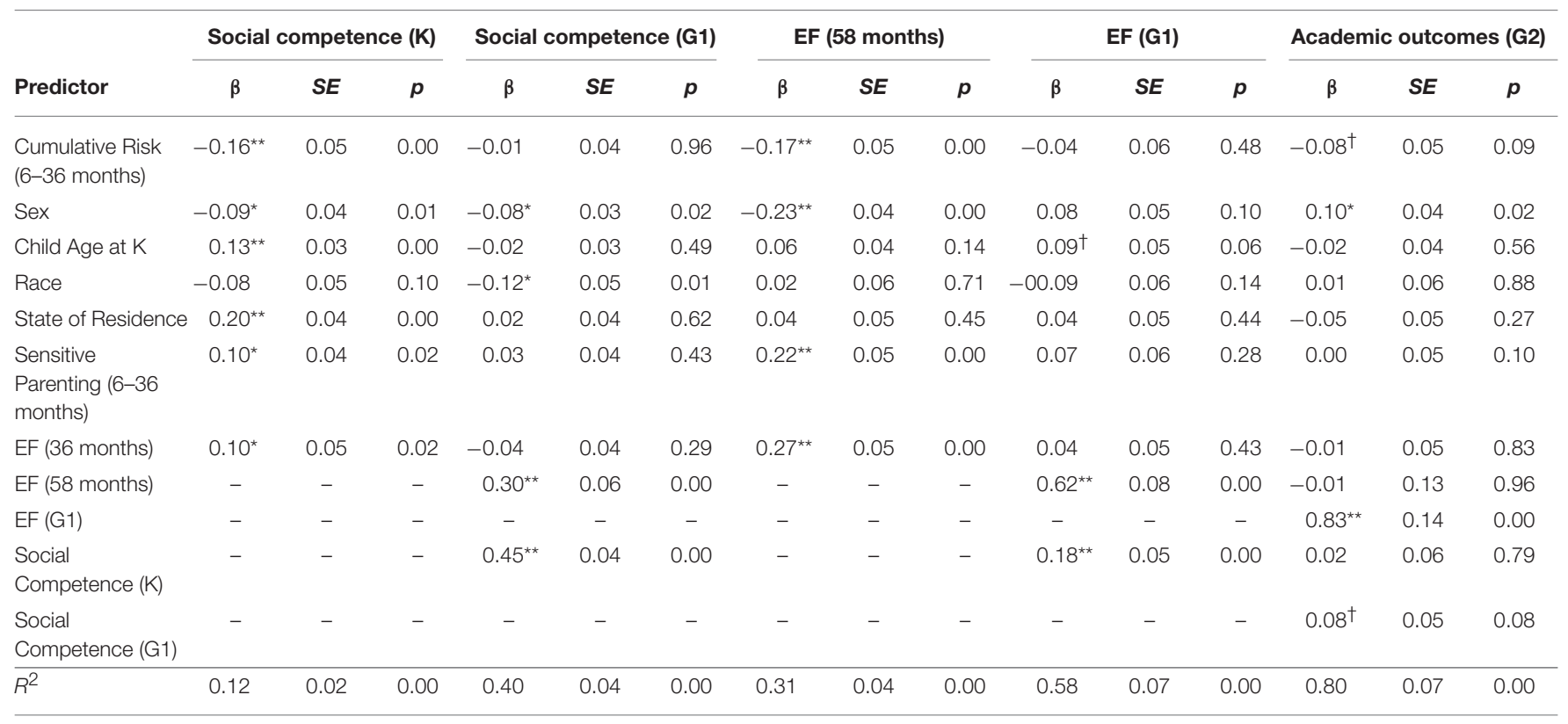

${ }^{\star} p<0.05,{ }^{* *} p<0.01,{ }^{\dagger} p<0.10$; All coefficients are standardized. EF, Executive Function; K, Kindergarten; G1, Grade 1; G2 = Grade 2.

as it relates to cumulative poverty-related risk and academic outcomes.

Here we tested the primary hypothesis that the development of $\mathrm{EF}$ and social competence reciprocally influence each other, such that EF through social competence (and vice versa) demonstrate cross-lagged mediation of poverty-related risk exposure and early academic abilities. Our findings provided partial support for this hypothesis, by revealing that social competence at $\mathrm{K}$ through $\mathrm{EF}$ at $\mathrm{G} 1$ significantly mediates the effect of poverty-related cumulative risk exposure 
TABLE 7 | Indirect effects of mediating pathways predicting academic outcomes.

\begin{tabular}{lccc}
\hline & \multicolumn{3}{c}{ Academic Outcomes G2 } \\
\cline { 2 - 4 } Predictor & $\beta$ & SE & $\begin{array}{c}95 \% \text { Confidence } \\
\text { Interval }\end{array}$ \\
\hline $\begin{array}{l}\text { Cumulative Risk } \rightarrow \text { Social Competence } \\
(K)\end{array}$ & -0.002 & 0.009 & $(-0.015,0.014)$ \\
$\begin{array}{l}\text { Cumulative Risk } \rightarrow \text { Social Competence } \\
(\text { G1) }\end{array}$ & 0.001 & 0.004 & $(-0.007,0.005)$ \\
$\begin{array}{l}\text { Cumulative Risk } \rightarrow \text { EF (58 months) } \\
\text { Cumulative Risk } \rightarrow \text { EF (G1) }\end{array}$ & 0.001 & 0.022 & $(-0.027,0.047)$ \\
$\begin{array}{l}\text { Cumulative Risk } \rightarrow \text { Social Competence } \\
(K) \rightarrow \text { Social Competence (G1) }\end{array}$ & -0.032 & 0.049 & $(-0.114,0.040)$ \\
$\begin{array}{l}\text { Cumulative Risk } \rightarrow \text { EF (58 months) } \rightarrow \\
\text { Social Competence (G1) }\end{array}$ & -0.003 & $(-0.012,0.000)$ \\
$\begin{array}{l}\text { Cumulative risk } \rightarrow \text { EF (58 months) } \rightarrow \\
\text { EF (G1) }\end{array}$ & $-0.085^{*}$ & 0.035 & $(-0.151,-0.038)$ \\
$\begin{array}{l}\text { Cumulative Risk } \rightarrow \text { Social Competence } \\
(K) \rightarrow \text { EF (G1) }\end{array}$ & $-0.024^{*}$ & 0.012 & $(-0.046,-0.009)$ \\
\end{tabular}

*Significant (confidence interval does not contain zero). All coefficients are standardized. EF, Executive Function; K, Kindergarten; G1, Grade 1, G2, Grade 2.

on G2 academic outcomes. More specifically, challenges in social competence at $\mathrm{K}$ associated with poverty-related risks negatively impacted academic abilities related to math and literacy skills through challenges in EF at G1. Importantly, our conservatively specified model allows for strong inference that social competence is meaningfully related to academic outcomes through EF at G1. Furthermore, our model demonstrated significant longitudinal mediation of the effect of cumulative risk on academic outcomes via $\mathrm{EF}$ at 58 months through $\mathrm{EF}$ at G1. However, our hypothesis was not fully supported, as the reciprocal pathway by which $\mathrm{EF}$ at $\mathrm{K}$ through social competence at G1 mediates the relationship between cumulative risk and academic outcomes was merely approaching significance.

These results converge with a growing literature indicating the importance of $\mathrm{EF}$ development for promoting early academic competence (Blair, 2002; Blair and Razza, 2007; Bierman et al., 2008; Willoughby et al., 2012b). Furthermore, these findings suggest that the development of EFs might be influenced by and/or functionally linked to the development of social competence, at least across early development. That is, our present findings suggest that disrupted social competence may influence the development of $\mathrm{EF}$ with implications for academic achievement in the early elementary grades. These findings are consistent with empirical research linking EF and social development (de Wilde et al., 2016; Holmes et al., 2016), as well as theoretical work regarding the interplay between EF and social development (Vygotsky, 1978; Riggs et al., 2006; Moriguchi, 2014). For example, both empirical and theoretical work converge on findings that positive, stable relationships are an active ingredient in facilitating cognitive development and maintaining higher-order cognitive abilities across the lifespan (Vygotsky, 1978; Baumeister et al., 2002, 2005).

Thus, our causal theory of relations between social competence and $\mathrm{EF}$ is based in prior empirical and theoretical work demonstrating that successful prosocial interactions require many tasks that rely on EFs, such as mentalizing another's ever-changing beliefs, expectations, and emotions, as well as maintaining focus, problem-solving and inhibitory control of inappropriate behaviors (Hughes and Ensor, 2007; Brock et al., 2009). In other words, successful prosocial interactions that are reliant upon social competence skills may serve as important, and perhaps even necessary, opportunities for continued practice and development of EF skills (Bateson, 2005; Russ, 2016). Such a conceptual model is consistent with long-standing approaches to the interrelation of social and cognitive development based on the theory of Vygotsky (Cole, 1995). However, in our conservatively specified model including early measures of $\mathrm{EF}$ and social competence, the mediational pathway of EF at 58 months through social competence at G1 was only approaching significance, and thus did not display strong convergence with prior work not including the earlier time points for these measures (Valiente et al., 2008, 2011). In our analysis, the effect of $\mathrm{EF}$ at 58 months on academic ability in G2 was mediated through EF measured in G1.

A goal of future research should be determining the mechanisms that underlie the developmental relations between social competence and EF development. From a developmental neuroscience perspective, previous studies have suggested that the development of the medial prefrontal cortex (mPFC) is functionally involved in emerging $\mathrm{EF}$ abilities, with structural variations mediating the relationship between early-life stress and EF skills (Arnsten and Li, 2005). While social skills are subserved by a diffuse, integrated neural network (McCabe et al., 2001; Decety et al., 2004), pathology of frontal regions has been associated with social difficulties (Rosema et al., 2012). Thus, disruption of social competence and EF, such as via socioeconomic disadvantage and its related stressors, may share altered $\mathrm{mPFC}$ development as a common underlying mechanism. Indeed, the mPFC has prolonged postnatal development, and is thus more susceptible to environmental influences (Noble et al., 2007; Kishiyama et al., 2009; Hackman et al., 2010).

The present study also provides novel, preliminary support for the premise that social competence through EF is a pathway by which poverty-related cumulative risk predicts early academic competence in a high-risk, low-income sample. The disruption of social development, such as via exposure to poverty-related stressors, may have a profound sequential effect on EF, serving as a causal pathway leading to broader achievement inequalities. These findings are consistent with, and extend, previous studies highlighting the importance of social competence and EF, individually, as important markers of school readiness (Campbell and Stauffenberg, 2008; Blair and Raver, 2015; Eickmann et al., 2016). Children with social skill problems participate less in classroom activities and social relations, have lower quality relationships with teachers and peers, and have decreased abilities in planning and completing academic tasks (Blair, 2002; de Wilde et al., 2016). Furthermore, it has been proposed that adverse social experiences and/or social stress as a result of poor social competence can impair regulatory resources, leading to a monopolization of EFs and impairment of cognitive functions (Baumeister et al., 2002; Davies et al., 2008). Consequently, problems with social competence and EF skills place children at risk of academic difficulties. However, the previous research has largely failed to consider the processes by which social and 
EF development, considered together, affect school readiness and academic performance, especially for at-risk children growing up in poverty. Here, by exploring possible mediational paths related to both EF and social development, we have provided evidence furthering the understanding of the longitudinal processes by which cumulative risk can influence academic ability.

The negative associations between poverty-related cumulative risk and social competence/EF development likely results from exposure to stressors that disrupt skill development. Growing up in conditions of low socioeconomic status affects children's outcomes in a multitude of ways. Low socioeconomic status families face significant economic and housing obstacles, among other barriers, that can diminish parent-infant relationship quality and socialization opportunities for children (Ryan et al., 2006). Disruptions in early social and emotional experiences, such as decreased sensitive and responsive caregiving, may set the stage for subsequent social competence and EF challenges. For example, low rates of parental sensitivity decrease opportunities for scaffolding of social behavior and emotional regulation, language exchange, and sustained joint attention (Goldsmith and Rogoff, 1997; Lengua et al., 2007).

Altogether, this study provided us with the opportunity to explore potential mechanisms regarding the impact of earlylife risk exposure on academic ability. Additionally, the use of autoregressive cross-lagged mediation provided the opportunity to identify how social competence and EF skills influence each other across development, serving as indirect pathways by which poverty-related risks might influence early academic abilities. Such methodology provides an important first step for understanding complex processes by which poverty-related stressors impacts child development, which can in turn inform preventative and remediating intervention efforts.

A major strength of this study was the use of a longitudinal prospective design, which allowed for a clearer definition of the relationship between cumulative poverty-related risk and the development of academic abilities in a large sample size $(N=1,292)$. Such design provides stronger evidence for causal order than cross-sectional designs. However, the current findings should be interpreted with the following limitations in mind. While exploring autoregressive cross-lagged mediation serves as an important first step for understanding potential complex processes and mechanisms underlying the relationship between cumulative risk and academic abilities, our analysis is based on correlative data. Human studies are fundamentally limited in the extent that they can establish causal mechanisms by which poverty-related adversity influences development (Perry et al., 2018). However, it is important to note that our inschool and in-home assessments yield important insights into real-world settings, providing our study with higher external validity. This study was additionally limited in its assessment of the multicomponent nature of poverty (Duncan and Magnuson, 2003). Here we utilized a cumulative risk framework based on prior research suggesting that the accumulation of risks is more related to poorer outcomes for children than any risk factor alone (e.g., Rutter, 1979; Burchinal et al., 2000, 2006). However, it is possible that specific poverty-related risk factors alone differentially influence academic achievement. Furthermore, our cumulative risk index is limited by its assumption that each poverty-related variable has equal influences on child outcome. Poverty-related risk factors oftentimes co-occur and are highly correlated, and thus it is difficult to tease apart cause-effect relationships to establish mechanisms regarding the multicomponent nature of poverty. Modeling distinct aspects of poverty through the use of animal models has the potential to help disentangle the cause-effect relationships between povertyrelated risk factors and child outcomes (Perry et al., 2018). An additional limitation is that we only measured social competence via teacher reports on behavior in school settings. Children have social experiences with peers outside the confines of these settings, which we failed to capture, and thus warrant attention in future research. Similarly, it is possible that teachers' ratings of child prosocial behaviors are specific to the classroom context and biased by perceptions of the child's academic skill-level. Expanding ways in which these constructs are measured in future research would strengthen the present study's findings and interpretations. Lastly, our statistical analysis does not allow for assessment of within person longitudinal changes, which should be the focus of future analyses.

In conclusion, we have provided the first evidence regarding potential autoregressive cross-lagged mediational pathways by which social competence and EF skills may disrupt academic achievement in a high-risk low-income sample. Importantly, we have demonstrated this in real-world contexts and longitudinally across a substantial, ecologically important time in young children's lives. In sum, longitudinal alterations in EF abilities across the early academic years may be one pathway by which poverty-related stressors influence academic abilities. Additionally, altered social competence may further disrupt EF development across formative years of elementary school for at-risk children from low-income families. Such findings suggest that social and EF development may be intrinsically linked, and should always be considered together, which provide important implications. From a preventative perspective, our findings support early screening, and an expansion of earlylife screening tools, for both prosocial and EF skills to identify at-risk individuals and foster early academic achievement. Importantly, both EF skills and social skills are malleable and rapidly developing in preschool years, making them feasible targets for preventative interventions to reduce socioecomonic inequality in academic achievement (Howes et al., 1998; Sasser et al., 2017). However, current interventions rarely place equal emphases on targeting $\mathrm{EF}$ and social competence together in practice (Bierman et al., 2008; Diamond and Lee, 2011; Christ et al., 2017; Lillard et al., 2017). Our findings promote the importance of integrating existing programs aimed at improving EF or social competence, to optimize the effectiveness of both interventions. In doing so, increasing the prevalence of children in impoverished neighborhoods who are both cognitively and socially ready to succeed in school may prove to be critical to ending lifelong achievement gaps and intergenerational poverty.

\section{ETHICS STATEMENT}

This study was carried out in accordance with the recommendations of the Institutional Review Board at Pennsylvania State University and the Office of Human 
Research Ethics at the University of North Carolina with written informed consent from all subjects. All subjects gave written informed consent in accordance with the Declaration of Helsinki.

\section{AUTHOR CONTRIBUTIONS}

$\mathrm{RP}, \mathrm{SB}$, and $\mathrm{CB}$ contributed to the conception and design of the study. RP performed statistical analyses and wrote the first draft of the manuscript. SB organized the database, performed statistical analyses, and wrote sections of the manuscript. All authors contributed to manuscript revision and read and approved the submitted version.

\section{FUNDING}

Human research was supported by the National Institute of Child Health and Human Development Grants P01HD03966701A1, P01HD039667-06, and R01HD081252. This material is

\section{REFERENCES}

Arnsten, A. F., and Li, B. M. (2005). Neurobiology of executive functions: catecholamine influences on prefrontal cortical functions. Biol. Psychiatry 57, 1377-1384. doi: 10.1016/j.biopsych.2004.08.019

Baptista, J., Osorio, A., Costa Martins, E., Verissimo, M., and Martins, C. (2016). Does social-behavioral adjustment mediate the relation between executive function and academic readiness? J. Appl. Dev. Psychol. 46, 22-30. doi: 10.1016/j.appdev.2016.05.004

Bateson, P. (2005). The Role of Play in the Evolution Of Great Apes and Humans. New York, NY: Guilford Press.

Baumeister, R. F., DeWall, C. N., Ciarocco, N. J., and Twenge, J. M. (2005). Social exclusion impairs self-regulation. J. Pers. Soc. Psychol. 88, 589-604. doi: 10.1037/0022-3514.88.4.589

Baumeister, R. F., Twenge, J. M., and Nuss, C. K. (2002). Effects of social exclusion on cognitive processes: anticipated aloneness reduces intelligent thought. J. Pers. Soc. Psychol. 83, 817-827. doi: 10.1037/0022-3514.83.4.817

Bibok, M. B., Carpendale, J. I., and Muller, U. (2009). Parental scaffolding and the development of executive function. New Dir. Child Adolesc. Dev. 2009, 17-34. doi: $10.1002 / \mathrm{cd} .233$

Bierman, K. L., Domitrovich, C. E., Nix, R. L., Gest, S. D., Welsh, J. A., Greenberg, M. T., et al. (2008). Promoting academic and social-emotional school readiness: the head start REDI program. Child Dev. 79, 1802-1817. doi: 10.1111/j.1467-8624.2008.01227.x

Blair, C. (2002). School readiness: Integrating cognition and emotion in a neurobiological conceptualization of children's functioning at school entry. Am. Psychol. 57, 111-127. doi: 10.1037/0003-066X.57.2.111

Blair, C., Granger, D. A., Willoughby, M., Mills-Koonce, R., Cox, M., Greenberg, M. T., et al. (2011). Salivary cortisol mediates effects of poverty and parenting on executive functions in early childhood. Child Dev. 82, 1970-1984. doi: 10.1111/j.1467-8624.2011.01643.x

Blair, C., and Raver, C. C. (2015). School readiness and self-regulation: a developmental psychobiological approach. Annu. Rev. Psychol. 66, 711-731. doi: 10.1146/annurev-psych-010814-015221

Blair, C., and Razza, R. P. (2007). Relating effortful control, executive function, and false belief understanding to emerging math and literacy ability in kindergarten. Child Dev. 78, 647-663. doi: 10.1111/j.1467-8624.2007.01019.x

Brock, L. L., Rimm-Kaufman, L., Nathanson, L., and Grimm, K. J. (2009). The contribution of 'hot' and 'cool' executive function to children's academic achievement and classroom behavior. Early Child. Res. Q. 24, 337-349. doi: 10.1016/j.ecresq.2009.06.001 based upon work supported by the National Science Foundation under Grant No. 1810208 awarded to RP. SB was supported by the National Science Foundation Graduate Research Fellowship Program under Grant No. DGE1342536. Any opinions, findings, and conclusions or recommendations expressed in this material are those of the author(s) and do not necessarily reflect the views of the National Science Foundation.

\section{ACKNOWLEDGMENTS}

The Family Life Project Phase I Key Investigators include: Lynne Vernon-Feagans, The University of North Carolina; Martha Cox, The University of North Carolina at Chapel Hill; Clancy Blair, New York University; Margaret Burchinal, The University of North Carolina; Patricia Garrett-Peters, The University of North Carolina; Mark Greenberg, The Pennsylvania State University; Roger Mills-Koonce, The University of North Carolina; and Michael Willoughby, RTI International. We thank the many families and research assistants for making this study possible.

Burchinal, M. R., Roberts, J. E., Hooper, S., and Zeisel, S. A. (2000). Cumulative risk and early cognitive development: a comparison of statistical risk models. Dev. Psychol. 36:7930807. doi: 10.1037/0012-1649.36.6.793

Burchinal, M. R., Roberts, J. E., Zeisel, S. A., Hennon, E. A., and Hooper, S. (2006). Risk and resiliency: protective factors in early elementary school years. Parent. Sci. Pract. 6, 79-113. doi: 10.1207/s15327922par0601_4

Campbell, S. B., and Stauffenberg, C. (2008). "Child characteristics and family processes that predict behavioral readiness for school," in Early Disparities in School Readiness: How Families Contribute to Transitions into School, eds A. C. A. Booth (Mahway, NJ: Erlbaum), 225-258.

Carlson, S. M. (2009). Social origins of executive function development. New Dir. Child Adolesc. Dev. 2009, 87-98. doi: 10.1002/cd.237

Christ, S. E., Stichter, J. P., O'Connor, K. V., Bodner, K., Moffitt, A. J. and Herzog, M. J. (2017). Social skills intervention participation and associated improvements in executive function performance. Autism Res. Treat. 2017:5843851. doi: 10.1155/2017/5843851

Ciairano, S., Visu-Petra, L., and Settanni, M. (2007). Executive inhibitory control and cooperative behavior during early school years: a follow-up study. $I$ Abnorm. Child Psychol. 35, 335-345. doi: 10.1007/s10802-006-9094-z

Cole, M. (1995). Culture and cognitive development: From cross-cultural research to creating systems of cultural mediation. Cult. Psychol. 1, 25-54.

Crook, S. R., and Evans, G. W. (2014). The role of planning skills in the incomeachievement gap. Child Dev. 85, 405-411. doi: 10.1111/cdev.12129

Davidson, M. C., Amso, D., Anderson, L. C., and Diamond, A. (2006). Development of cognitive control and executive functions from 4 to 13 years: evidence from manipulations of memory, inhibition, and task switching. Neuropsychologia 44, 2037-2078. doi: 10.1016/j.neuropsychologia.2006.02.006

Davies, P. T., Woitach, M. J., Winter, M. A., and Cummings, E. M. (2008). Children's insecure representations of the interparental relationship and their school adjustment: the mediating role of attention difficulties. Child Dev. 79, 1570-1582. doi: 10.1111/j.1467-8624.2008.01206.x.

Davis, H. L., and Pratt, C. (1996). The development of children's theory of mind: the working memory explanation. Aust. J. Psychol. 47, 25-31.

de Wilde, A., Koot, H. M., and van Lier, P. A. (2016). Developmental links between children's working memory and their social relations with teachers and peers in the early school years. J. Abnorm. Child Psychol. 44, 19-30. doi: 10.1007/s10802-015-0053-4

Decety, J., Jackson, P. L., Sommerville, J. A., Chaminade, T., and Meltzoff, A. N. (2004). The neural bases of cooperation and competition: an fMRI investigation. Neuroimage 23, 744-751. doi: 10.1016/j.neuroimage.2004. 05.025 
Denham, S. A., Kalb, S., Way, E., Warren-Khot, H., Rhoades, B. L., and Bassett, H. H. (2013). Social and emotional information processing in preschoolers: indicator of early school success? Early Child Dev. Care, 183, 667-688. doi: 10.1080/03004430.2012.682728

Diamond, A. (2013). Executive functions. Annu. Rev. Psychol. 64, 135-168. doi: 10.1146/annurev-psych-113011-143750

Diamond, A., and Lee, K. (2011). Interventions shown to aid executive function development in children 4 to 12 years old. Science 333, 959-964. doi: 10.1126/science.1204529

Dodge, K. A., Pettit, G. S., and Bates, J. E. (1994). Socialization mediators of the relation between socioeconomic status and child conduct problems. Child Dev. 65(2 Spec No), 649-665.

Duncan, G. J., and Magnuson, K. A. (2003). "Off with Hollingshead: Socioeconomic resources, parenting, and child development," in Socioeconomic status, parenting, and child development, eds M. H. Bornstein and R. H. Bradley (Mahwah, NJ: Erlbaum), 83-106.

Durston, S., Thomas, K. M., Worden, M. S., Yang, Y., and Casey, B. J. (2002). The effect of preceding context on inhibition: an event-related fMRI study. Neuroimage 16, 449-453. doi: 10.1006/nimg.2002.1074

Eickmann, S. H., Emond, A. M., and Lima, M. (2016). Evaluation of child development: beyond the neuromotor aspect. J Pediatr. 92(3 Suppl. 1), S71-83. doi: 10.1016/j.jped.2016.01.007

Elias, M. J., and Haynes, N. M. (2008). Social competence, social support, and academic achievement in minority, low-income, urban elementary school children. School Psychol. Q. 23, 474-495. doi: 10.1037/1045-3830.23.4.474

Enders, C. K. (2010). Applied Missing Data Analysis. New York, NY: Guilford Press.

Engle, P. L., and Black, M. M. (2008). The effect of poverty on child development and educational outcomes. Ann. N. Y. Acad. Sci. 1136, 243-256. doi: 10.1196/annals.1425.023

Engle, R. W. (2002). Working memory capacity as executive attention. Curr. Dir. Psychol. Sci. 11, 19-23. doi: 10.1111/1467-8721.00160

Evans, G. W., Li, D., and Whipple, S. S. (2013). Cumulative risk and child development. Psychol. Bull. 139, 1342-1396. doi: 10.1037/a0031808

Goldsmith, D. F., and Rogoff, B. (1997). Mothers' and toddlers, coordinated joint focus of attention: variations with maternal dysphoric symptoms. Dev. Psychol. 33, 113-119.

Goodman, R. (1997). The Strengths and Difficulties Questionnaire: a research note. J. Child Psychol. Psychiatry 38, 581-586.

Hackman, D. A., Farah, M. J., and Meaney, M. J. (2010). Socioeconomic status and the brain: mechanistic insights from human and animal research. Nat. Rev. Neurosci. 11, 651-659. doi: 10.1038/nrn2897

Holmes, C. J., Kim-Spoon, J., and Deater-Deckard, K. (2016). Linking executive function and peer problems from early childhood through middle adolescence. J. Abnorm. Child Psychol. 44, 31-42. doi: 10.1007/s10802-015-0044-5

Howes, C., Burchinal, M., Pianta, R., Bryant, D., Early, D., Clifford, R., et al. (2008). Ready to learn? Children's pre-academic achievement in pre-Kindergarten programs. Early Child. Res. Q. 23, 27-50. doi: 10.1016/j.ecresq.2007.05.002

Howes, C., Hamilton, C. E., and Phillipsen, L. C. (1998). Stability and continuity of child-caregiver and child-peer relationships. Child Dev. 69, 418-426.

Huffman, L. C., Mehlinger, S. L., Kerivan, A. S., Cavanaugh, D. A., Lippitt, J., and Moyo, O. (2001). Off to a Good Start: Research on the Risk Factors for Early School Problems and Selected Federal Policies Affecting Children's Social and Emotional Development and Their Readiness for School, 1-231. Available online at: https://eric.ed.gov/?id=ED476378

Hughes, C., and Ensor, R. (2007). Executive function and theory of mind: predictive relations from ages 2 to 4. Dev. Psychol. 43, 1447-1459. doi: 10.1037/0012-1649.43.6.1447

Hughes, C., Ensor, R., Wilson, A., and Graham, A. (2010). Tracking executive function across the transition to school: a latent variable approach. Dev. Neuropsychol. 35, 20-36. doi: 10.1080/87565640903325691

Hughes, C. H., and Ensor, R. A. (2009). How do families help or hinder the emergence of early executive function? New Dir. Child Adolesc. Dev. 2009, 35-50. doi: 10.1002/cd.234

Jacobson, L. A., Williford, A. P., and Pianta, R. C. (2011). The role of executive function in children's competent adjustment to middle school. Child Neuropsychol. 17, 255-280. doi: 10.1080/09297049.2010.535654
Jacques, S., and Zelazo, P. D. (2001). The Flexible Item Selection Task (FIST): a measure of executive function in preschoolers. Dev. Neuropsychol. 20, 573-591. doi: 10.1207/S15326942DN2003_2

Kaiser, A. P., Hancock, T. B., Cai, X. S., Foster, E. M., and Hester, P. P. (2000). Parent-reported behavioral problems and language delay in boys and girls enrolled in Head Start classrooms. Behav. Disord. 26, 6-41. doi: 10.1177/019874290002600104

Kishiyama, M. M., Boyce, W. T., Jimenez, A. M., Perry, L. M., and Knight, R. T. (2009). Socioeconomic disparities affect prefrontal function in children. J. Cogn. Neurosci. 21, 1106-1115. doi: 10.1162/jocn.2009.21101

Kline, R. B. (2015). Principles and Practice of Structural Equation Modeling, 4th Edn. New York, NY: Guilford publications.

Lacour, M., and Tissington, L. D. (2011). The effects of poverty on academic achievement. Educ. Res. Rev. 6, 522-527.

Ladd, G., and Profilet, S. (1996). The child behavior scale: a teacher report measure of young children's aggressive, withdrawn, and prosocial behaviors. Dev. Psychol. 32, 1008-1024.

Landry, S. H., Miller-Loncar, C. L., Smith, K. E., and Swank, P. R. (2002). The role of early parenting in children's development of executive processes. Dev. Neuropsychol. 21, 15-41. doi: 10.1207/S15326942DN2101_2

Lengua, L. J., Honorado, E., and Bush, N. R. (2007). Contextual risk and parenting as predictors of effortful control and social competence in preschool children. J. Appl. Dev. Psychol. 28, 40-55. doi: 10.1016/j.appdev.2006. 10.001

Lewis, C., and Carpendale, J. I. (2009). Introduction: links between social interaction and executive function. New Dir. Child Adolesc. Dev. 2009, 1-15. doi: $10.1002 / \mathrm{cd} .232$

Lillard, A. S., Heise, M. J., Richey, E. M., Tong, X., Hart, A., and Bray, P. M. (2017) Montessori preschool elevates and equalizes child outcomes: a longitudinal study. Front. Psychol. 8:1783. doi: 10.3389/fpsyg.2017.01783

Lindsey, E. W., and Colwell, M. J. (2003). Preschoolers' emotional competence: links to pretend and physical play. Child Study J. 33, 39-52.

Luria, A. R. (1966). Higher Cortical Functions in Man, 1st Edn. New York, NY: Basic Books.

McCabe, K., Houser, D., Ryan, L., Smith, V., and Trouard, T. (2001). A functional imaging study of cooperation in two-person reciprocal exchange. Proc. Natl. Acad. Sci. U S A. 98, 11832-11835. doi: 10.1073/pnas.2114 15698

McClelland, M. M., Acock, A. C., and Morrison, F. J. (2006). The impact of kindergarten learning-related skills on academic trajectories at the end of elementary school. Early Child. Res. Q. 21, 471-490. doi: 10.1016/j.ecresq.2006.09.003

Mills-Koonce, W. R., Appleyard, K., Barnett, M., Deng, M., Putallaz, M., and Cox, M. (2011). Adult attachment style and stress as risk factors for early maternal sensitivity and negativity. Infant Ment. Health J. 32, 277-285. doi: 10.1002/imhj.20296

Moriguchi, Y. (2014). The early development of executive function and its relation to social interaction: a brief review. Front. Psychol. 5:388. doi: $10.3389 /$ fpsyg.2014.00388

Murray, C., and Malmgren, K. (2005). Implementing a teacher-student relationship program in a high-poverty urban school: effects on social, emotional, and academic adjustment and lessons learned. J. Sch. Psychol. 43, 137-152. doi: 10.1016/j.jsp.2005.01.003

Muthén, L. K., and Muthén, B. O. (1998-2012). Mplus User's Guide, 7th Edn. Los Angeles, CA: Muthén \& Muthén.

Nakao, K., and Treas, J. (1994). Updating job prestige and socioeconomic scores: how the new measures measure up. Sociol. Methodol. 24, 1-72.

National Institute of Child Health and Human Development Early Child Care Research Network (1999). Child care and mother-child interaction in the first 3 years of life. Dev. Psychol. 35, 1399-1413.

Nesbitt, K. T., Baker-Ward, L., and Willoughby, M. (2013). Executive function mediates socio-economic and racial differences in early academic achievement. Early Child. Res. Q. 28, 774-783. doi: 10.1016/j.ecresq.2013.07.005

Noble, K. G., McCandliss, B. D., and Farah, M. J. (2007). Socioeconomic gradients predict individual differences in neurocognitive abilities. Dev. Sci. 10, 464-480. doi: $10.1111 /$ j.1467-7687.2007.00600.x 
Oberle, E., and Reichl, K. (2013). Relations among peer acceptance, inhibitory control, and math achievement in early adolescence. J. Appl. Dev. Psychol. 34, 45-51. doi: 10.1016/j.appdev.2012.09.003

Perry, R. E., Finegood, E. D., Braren, S. H., Dejoseph, M. L., Putrino, D. F., Wilson, D. A., et al. (2018). Developing a neurobehavioral animal model of poverty: drawing cross-species connections between environments of scarcityadversity, parenting quality, and infant outcome. Dev. Psychopathol. 1-20. doi: 10.1017/S095457941800007X

Peterson, J. B., and Flanders, J. L. (2005). Play and the Regulation of Aggression. New York, NY: Guilford Press.

Preacher, K. J., and Hayes, A. F. (2008). Effect size measures for mediation models: quantitative strategies for communicating indirect effects. Behav. Res. Methods 40, 879-891. doi: 10.1037/a0022658

Raver, C. C., Blair, C., and Willoughby, M. (2013). Poverty as a predictor of 4-year-olds' executive function: new perspectives on models of differential susceptibility. Dev. Psychol. 49, 292-304. doi: 10.1037/a0028343

Raver, C. C., and Zigler, E. F. (1997). Social competence: an untapped dimension in evaluating head start's success. Early Child. Res. Q. 12, 363-385. doi: 10.1016/S0885-2006(97)90017-X

Rhoades, B. L., Greenberg, M. T., and Domitrovich, C. E. (2009). The contribution of inhibitory control to preschoolers' social-emotional competence. J. Appl. Dev. Psychol. 30, 310-320. doi: 10.1016/j.appdev.2008.12.012

Riggs, N. R., Blair, C., and Greenberg, M. T. (2004). Concurrent and 2-year longitudinal relations between executive function and the behavior of 1st and 2nd grade children. Child Neuropsychol. 9, 267-276. doi: 10.1076/chin.9.4.267.23513

Riggs, N. R., Jahromi, L. B., Razza, R. P., Dillworth-Bart, J. E., and Mueller, U. (2006). Executive function and the promotion of social-emotional competence. J. Appl. Dev. Psychol. 27, 300-309. doi: 10.1016/j.appdev.2006.04.002

Rosema, S., Crowe, L., and Anderson, V. (2012). Social function in children and adolescents after traumatic brain injury: a systematic review 1989-2011. J. Neurotrauma 29, 1277-1291. doi: 10.1089/neu.2011.2144

Roskam, I., Stievenart, M., Meunier, J. C., and Noël, M. P. (2014). The development of children's inhibition: does parenting matter? J. Exp. Child Psychol. 122, 166-182. doi: 10.1016/j.jecp.2014.01.003

Russ, S. W. (2016). Pretend play: antecedent of adult creativity. New Dir. Child Adolesc. Dev. 2016, 21-32. doi: 10.1002/cad.20154

Rutter, M. (1979). Psychosocial resilience and protective mechanisms. Am. J. Orthopsych. 57, 316-333.

Ryan, R. M., Fauth, R. C., and Brooks-Gunn, J. (2006). Childhood Poverty: Implications for School Readiness and Early Childhood Education, 2nd Edn. Mahwah, NJ: Erlbaum.

Sasser, T. R., Bierman, K. L., Heinrichs, B., and Nix, R. L. (2017). Preschool intervention can promote sustained growth in the executive-function skills of children exhibiting early deficits. Psychol. Sci. 28, 1719-1730. doi: $10.1177 / 0956797617711640$

Shrout, P. E., and Bolger, N. (2002). Mediation in experimental and nonexperimental studies: new procedures and recommendations. Psychol. Methods 7, 422-445. doi: 10.1037//1082-989X.7.4.422

Solano, I. S., and Weyer, M. (2017). Closing the opportunity gap in early childhood education. NCSL Legisbrief 25, 1-2.

Stone, L. L., Otten, R., Engels, R. C., Vermulst, A. A., and Janssens, J. M. (2010). Psychometric properties of the parent and teacher versions of the strengths and difficulties questionnaire for 4- to 12-year-olds: a review. Clin. Child Fam. Psychol. Rev. 13, 254-274. doi: 10.1007/s10567-0100071-2
Sulik, M. J., Blair, C., Mills-Koonce, R., Berry, D., Greenberg, M., and Family Life Project, I. (2015). Early parenting and the development of externalizing behavior problems: longitudinal mediation through children's executive function. Child Dev. 86, 1588-1603. doi: 10.1111/cdev.12386

Valiente, C., Eisenberg, N., Haugen, R., Spinrad, T. L., Hofer, C., Liew, J., et al. (2011). Children's effortful control and academic achievement: mediation through social functioning. Early Educ. Dev. 22, 411-433. doi: 10.1080/10409289.2010.505259

Valiente, C., Lemery-Chalfant, K., Swanson, J., and Reiser, M. (2008) Prediction of children's academic competence from their effortful control, relationships, and classroom participation. J. Educ. Psychol. 100, 67-77. doi: 10.1037/0022-0663.100.1.67

van Lier, P. A., and Deater-Deckard, K. (2016). Children's elementary school social experience and executive functions development: introduction to a special section. J. Abnorm. Child Psychol. 44, 1-6. doi: 10.1007/s10802-015-0113-9

Vernon-Feagans, L., Cox, M., and FLF Key Investigators. (2013). The Family Life Project: an epidemiological and developmental study of young children living in poor rural communities. Monogr. Soc. Res. Child Dev. 78, 1-150, vii. doi: $10.1111 /$ mono.12046

Vygotsky, L. S. (1978). Mind in Society: The Development of Higher Psychological Processes. Cambridge: Harvard University Press.

Wasik, B. A., Bond, M. A., and Hindman, A. (2006). The effects of a language and literacy intervention on Head Start children and teachers. J. Educ. Psychol. 98, 63-74. doi: 10.1037/0022-0663.98.1.63

Willoughby, M., and Blair, C. (2011). Test-retest reliability of a new executive function battery for use in early childhood. Child Neuropsychol. 17, 564-579. doi: 10.1080/09297049.2011.554390

Willoughby, M. T., Blair, C. B., Wirth, R. J., and Greenberg, M. (2010). The measurement of executive function at age 3 years: psychometric properties and criterion validity of a new battery of tasks. Psychol. Assess. 22, 306-317. doi: $10.1037 / \mathrm{a} 0018708$

Willoughby, M. T., Blair, C. B., Wirth, R. J., and Greenberg, M. (2012b). The measurement of executive function at age 5: psychometric properties and relationship to academic achievement. Psychol. Assess. 24, 226-239. doi: $10.1037 / \mathrm{a} 0025361$

Willoughby, M. T., Wirth, R. J., and Blair, C. B. (2011). Contributions of modern measurement theory to measuring executive function in early childhood: an empirical demonstration. J. Exp. Child Psychol. 108, 414-435. doi: 10.1016/j.jecp.2010.04.007

Willoughby, M. T., Wirth, R. J., Blair, C. B., and Family Life Project, I. (2012a). Executive function in early childhood: longitudinal measurement invariance and developmental change. Psychol. Assess. 24, 418-431. doi: 10.1037/a0025779

Woodcock, R. W., McGrew, K., and Mather, N. (2001). The Woodcock-Johnson Tests of Achievement, $3 r d$ Edn. Itasca, IL: Riverside.

Conflict of Interest Statement: The authors declare that the research was conducted in the absence of any commercial or financial relationships that could be construed as a potential conflict of interest.

Copyright (C) 2018 Perry, Braren, Blair and the Family Life Project Key Investigators. This is an open-access article distributed under the terms of the Creative Commons Attribution License (CC BY). The use, distribution or reproduction in other forums is permitted, provided the original author(s) and the copyright owner(s) are credited and that the original publication in this journal is cited, in accordance with accepted academic practice. No use, distribution or reproduction is permitted which does not comply with these terms. 